\section{Reproductive tract infections among women attending gynaecology outpatient department Bohara MS, ${ }^{1 *}$ Joshi AB, ${ }^{2}$ Lekhak B, ${ }^{3}$ Gurung G ${ }^{2}$}

\author{
${ }^{1}$ Department of Microbiology TU, Siddhanathn \\ Science Campus Mahendranagar, ${ }^{2}$ Institute of \\ Medicine, TUTH, Maharajang, Kathmandu, ${ }^{3}$ Central \\ Department of Microbiology, TU, Kirtipur
}

\begin{abstract}
BACKGROUND: Women often suffer silently with reproductive tract infections (RTIs) and sexually active young women are particularly susceptible to sexually transmitted Infections (STIs). The study aimed to know the prevalence of reproductive tract infections among married women attending Gynecological Outpatients Department of Tribhuvan University Teaching Hospital (TUTH), Kathmandu, Nepal.
\end{abstract}

MATERIALS AND METHODS: A hospital based crosssectional design was used to investigate RTIs among women attending outpatients department of Gynae and Obstetrics, TUTH from July to November, 2006. A total of 208 samples from 104 women were examined microscopically and culture using standard microbial technique to investigate etiological agents of RTIs. Study samples were selected and examined on the basis of either having discharge or complaints of lower abdominal pain.

RESULTS: A total of 208 samples collected from 104 patients were examined and 26\% samples were positive for different causative agents of RTIs. Thirty percent of women reported having symptoms related to RTIs and was common in young married women. Nineteen percent had STIs. Thirteen percent had trichomonasis and 7\% had gonorrhoea identified in Gram stained smears and cultures. Many women had endogenous RTIs. Bacterial vaginosis was diagnosed in $15 \%$ and vaginal candidiasis in $25 \%$ of women.

CONCLUSIONS: Yong married women have a high prevalence of RTIs. Education and outreach programs are needed to reduce embarrassment and lack of knowledge related to RTIs. The low socio-economic status of women appears to have influence on high rate of infections.

KEYWORDS: Gynecological department, Married women, Reproductive tract infections, TUTH

Article submitted 10 July. Reviewed 19 August. Author correction 28 August. Final version accepted 15 September 2012 


\section{INTRODUCTION}

Many women and men suffer from reproductive tract infections (RTIs), including sexually transmitted infections (STIs). Sexually transmitted diseases (STD) continue to be a major and growing public health problem in many parts of the world, especially in developing countries where estimated 340 million new cases of curable STIs occur each year, and 151 million of them in South and South Asia alone. ${ }^{1}$

STIs are among the top five disease categories and about one third of STIs globally occur among people younger than 25 years of age. ${ }^{2}$ WHO estimated that 400,000 new cases of STIs occur daily in the South East Asian Region (SEAR) alone. ${ }^{3}$ Centers for Disease Control (CDC) estimates that 19 million new infections occur each year, almost half of them among young people age 15 to 24 years. ${ }^{4}$

STIs are also common in Nepal. The high prevalence of STI in Far Western and Mid Western regions of Nepal could be attributed to the presence of certain communities like Deuki and Badi, who are engaged in commercial sex and have been found to be suffering from STIs. ${ }^{5}$ RTI often cause discomfort and there is a loss of economic productivity. The most serious long term sequelae in women are pelvic inflammatory disease (PID), infertility and cervical cancer, the latter of which may lead to maternal death. ${ }^{6}$ The prevalence of STIs increases the risk of the acquiring and transmitting HIV infections by three to five times. ${ }^{7}$ In Nepal, women are reluctant to seek medical treatment because of lack of privacy, lack of female doctor at the health facility and higher cost of treatment. The reluctance is exacerbated when symptoms are embarrassing, as they are with RTIs, especially among adolescents.

The gynecology morbidity was high among the female because still they keep secret about their gynecological problems. ${ }^{8}$ Furthermore, women, more so than men, tend to regard RTI symptoms as normal discomfort and therefore often do not seek treatment. ${ }^{9}$ The distribution of different RTIs such as Trichmonasis (14\%), Gonorrhoea (9\%), Bacterial Vaginosis (16\% ) and Vaginal Candidiasis (34\%) was found among the patients visiting at TUTH. ${ }^{12}$ The RTIs among young married women is understudied in patients visiting this centre. hence we studied the prevalence of RTIs among married women attending Gynecological Outpatients Department of Tribhuvan University Teaching Hospital (TUTH), Kathmandu, Nepal.

\section{METHODS}

A hospital based, cross-sectional study was conducted from July to November 2006 at outpatients department of Gynecology, TUTH to investigate RTIs among married women aged 1549 years.

A total of 208 samples (104 vaginal discharge and 104 endocervical discharge) were collected. Study samples were selected from patients either having vaginal discharge or complaints of lower abdominal pain in women aged 15-49 years. Trichomonasis, gonorrhea, bacterial vaginosis, and vaginal candidiasis and other parameters like socio-demographic, educational, marital, reproductive status were investigated. Syphilis and Chlamydial infection were not investigated. Unmarried women in whom a speculum examination was not deemed culturally appropriate were not included in the study. Pregnant women reported of having missed periods, active bleeding per vagina or with history of birth in the previous six weeks were not included in the study. RTIs were diagnosed as mentioned in table 1.11

Ethical approval was taken from the Institutional Review Board, Institute of Medicine, Maharajgunj, and Kathmandu. Prior verbal and written consent was taken from all patients. A standard questionnaire was developed to collect the patient characteristics and consent was taken from respondents and hospital then administered to each patient. The collected data were entered and analyzed by using Statistical Package of Social Sciences version 16 (SPSS v 16). Chi-square test $\left(\chi^{2}\right)$ was used to compare the categorical data.

\section{RESULTS}

One hundred four patients were included in the study. The mean age of the women was 35.5 years. Majority of the women were illiterate and belonged to Brahmin ethnic group (33\%) (Table 2). Regarding occupation of husbands, most of them were salaried workers (32\%), followed by laborer (22 \%), small business (13\%), military (12\%), farmers $(11 \%)$, transport workers (5\%) and remaining $5 \%$ had other occupations (data not shown).

Women's' mean age at menarche was 14.5 years and mean age at marriage was 18 years. The majority had been pregnant twice or thrice and had two children but $10 \%$ had never been pregnant. 
Table 1. Diagnostic criterion for laboratory -diagnosed RTIs and other gynecologic conditions ${ }^{11}$

\begin{tabular}{ll}
\hline Laboratory-Diagnosed RTIs & \multicolumn{1}{c}{ Diagnosis Criteria } \\
STIs & $\begin{array}{l}\text { Positive wet mount preparation test } \\
\text { Isolation of Neisseria gonorrhoeae from cervical culture or } \\
\text { identification of gram- negative intracellular diplococci in Gram- } \\
\text { stained cervical smear }\end{array}$ \\
Endogenous infections & Trichomonasis \\
- $\quad$ Bacterial vaginosis & $\begin{array}{l}\text { Presence of at least three of the following: (a) Positive amine test } \\
\text { (b) presence of clue cells in Gram-stained vaginal smear (c) vaginal } \\
\text { fluid pH }>4.5 \text { and (d) Homogenous white gray discharge that stick } \\
\text { the vaginal walls } \\
\text { Positive culture for Candida with the presence of clinical sign (red } \\
\text { inflamed tissue and curdy white discharge) }\end{array}$ \\
\hline
\end{tabular}

Table 2. Educational status of patients

\begin{tabular}{|c|c|c|c|c|}
\hline \multirow{3}{*}{ Education } & \multicolumn{3}{|c|}{ RTIs $(n=104)$} & \multirow{3}{*}{$\chi^{2}$ value } \\
\hline & Yes & No & Total & \\
\hline & n (\%) & n (\%) & & \\
\hline Illiterate & $17(44)$ & $22(56)$ & 39 & 8.52 \\
\hline Primary & $5(23)$ & $17(77)$ & 22 & \\
\hline High school & $5(23)$ & $17(77)$ & 22 & \\
\hline College and University & $2(10)$ & $19(90)$ & 21 & \\
\hline Total & 29 & 75 & 104 & \\
\hline
\end{tabular}

Majority of women were living with their husband, one woman was widowed, two women were divorced, $10 \%$ of the women were separated from husband and $14 \%$ of their husbands were living away from home (data not shown). Thirty percent of women reported having gynecological symptoms. A total of 208 samples (104 vaginal discharges and 104 endocervical discharge) from 104 patients were examined. Out of which $26 \%$ samples were positive for different causative agents of RTIs.

Overall, $60 \%$ of the women had laboratorydiagnosed RTIs (Table 3). Among the 104 women who reported excessive vaginal discharge, $62 \%$ had RTIs, according to the laboratory finding (Not shown). Fifteen percent women reported still birth among them; $25 \%$ had RTIs and 44\% had endogenous infections. Seven percent women had miscarriage; $29 \%$ had RTIs and $29 \%$ had endogenous infection among them. Most of the women who had RTIs were in age group 25-35 years however this was insignificant (Table 4).

\section{DISCUSSION}

A total positive RTI cases were $26.4 \%$ detected by examination of vaginal and endocervical swabs. Among the positive, the vaginal swabs showed $61.5 \%$ and endocervial swabs showed $7 \%$ positive for different etiological agents of RTIs, a rate well correlated with study conducted in TUTH Nepal. ${ }^{12}$ Four types of microorganisms have been identified, where most predominant organism was Candida albicans $25 \%$. The prevalence rate was followed by G. vaginalis $14.4 \%$, Trichomonas vaginalis $12.5 \%$, and Neisseria gonorrhoeae $6.7 \%$ intracellular diplococci 5.8\%. These different aetological agents of RTIs are highly related to each other $\left(\chi^{2}\right.$ calculated value is much grated than tabulated value). These all types of infection are transmitted by similar type of mode of transmission. Those finding were similar to another study conducted at TUTH, the prevalence of Trichomonas vaginalis $13.8 \%, \quad$. vaginalis 15.59\%, Candida albicans 23.9\%, Neisseria gonorrhoeae 8.8\%, Gram-negative intracellular diplococci $6.4 \%$ (Table 5). ${ }^{12}$ Bacterial infections of the genital tract are common and cause significant morbidity. In a study carried out in South the incidence of sexually transmitted infection were $G$. vaginalis $6.2 \%$ and N. Gonorrohea $5.7 \% .^{21}$

The proportion of women experiencing RTIs was high in the patients studied. Most of the women with RTIs were in age group 25- 35 years, were married and living with husbands. However, no significant relationship was established between age group and RTIs syndrome $(\mathrm{P}>0.05)$. Rates of laboratory-diagnosed RTIs in this study were 
Table 3. Laboratory diagnosed RTIs and other gynecological condition, by presence of symptoms

\begin{tabular}{|c|c|c|c|c|c|}
\hline \multirow[t]{2}{*}{ RTIs } & & Yes, & No & \multirow[t]{2}{*}{ Total } & \multirow[t]{2}{*}{$\chi^{2}$ value } \\
\hline & & $\mathrm{n}(\%)$ & $\mathrm{n}(\%)$ & & \\
\hline \multirow[t]{2}{*}{ STIs } & Trichomonasis & $13(13)$ & $87(87)$ & 104 & 61.03 \\
\hline & Gonorrhoea & $7(7)$ & $97(93)$ & 104 & \\
\hline \multirow[t]{3}{*}{ Endogenous infection } & Bacterial vaginosis & $16(15)$ & $84(85)$ & 104 & \\
\hline & Vaginal candidiasis & $26(25)$ & $78(75)$ & 104 & \\
\hline & Total & 62 & 346 & 416 & \\
\hline
\end{tabular}

RTIs, reproductive tract infectiosn; STIs, Sexually transmitted infectons

Table 4. Correlation between age group and RTIs syndrome

\begin{tabular}{lcccc}
\hline Age groups (Years) & Yes & No & Total & $\chi^{2}$ value \\
\hline & & & & 1.76 \\
\hline Up to 35 & 33 & 22 & 55 & \\
Above 35 & 18 & 27 & 45 & \\
Total & 51 & 49 & 100 & \\
\hline
\end{tabular}

generally lower than those found Maharastra State of India, Nigeria and Nairobi study but infection rate was higher than Tamilnadu India, and Bangladesh. ${ }^{15}, 18,20,14,19$ The infection rate is quite similar to another study in Nepal, New Guinea. ${ }^{12,} 16$ The higher rate in the other studies may be attributed to a wider age range of participants and the fact that adolescent women had been sexually active. It is difficult to compare the incidence of STIs in one region with that of other because of different medical, social and economical factors. RTIs rate were much low in Bangladesh and Tamilnadu and much higher in the Maharastra state of India.19,14,15 The variations may be caused by differences in sexual norms and practices, which may affect exposure to RTIs, as well as by difference in willingness to report symptoms or be examined. Women in rural Bangladesh may be more secluded Neisseria gonorrhoeae is associated with behavior of persons. Nepal is still largely a traditional and live in more conservative sexual milieu. ${ }^{13}$ By contrast, social values in tribal areas such as that in the Maharastra state of India study commonly allow more sexual freedom. ${ }^{19}$

In this study gonococcal infection rate was much higher than elsewhere. ${ }^{15}$, 16, 17,18,19,20 The organism Neisseria gonorrhoeae is associated with behavior of persons. Nepal is still largely a traditional country and multiple sex partners of married women are very rare due to cultural, legal and social taboos. The high prevalence might be due to their husbands having multiple sexual practices. High prevalence was found among the laborers' wife. It might be due to unsafe multiple sexual practices, low economic status, lack of education, poor living standard, ignorance and difficulty in accessibility of immediate health care facilities may also attribute to higher rate of STDs.

\section{CONCLUSIONS}

Prevalence rate of RTI/STIs was high in illiterate, low socioeconomic status women; vaginal discharge (one of the most important selection criteria), occupation and education were found to

Table 5. Comparison of laboratory diagnosed RTIs with women across the seven countries

\begin{tabular}{|c|c|c|c|c|c|c|c|c|c|}
\hline 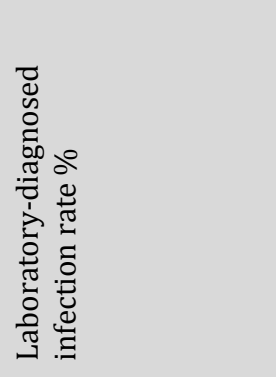 & 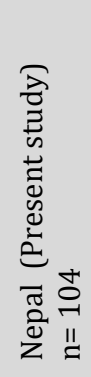 & 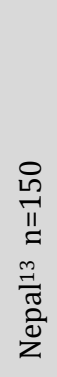 & 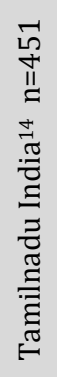 & 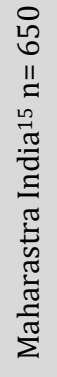 & 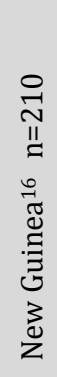 & 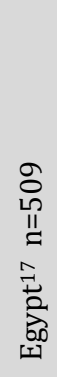 & 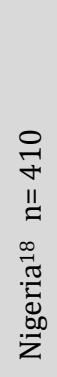 & 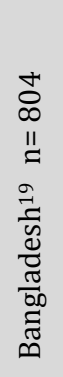 & 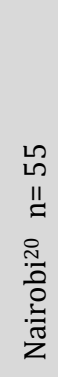 \\
\hline Trichomonasis & 13 & 14 & 1 & 14 & 46 & 18 & 9 & 0.8 & 20 \\
\hline Gonorrhoea & 7 & 9 & 10 & 3 & 1 & 0 & 3 & 5 & 3 \\
\hline Bacetrial Vaginosis & 14 & 16 & \# & 62 & \# & 9 & 22 & 6 & 21 \\
\hline Vaginal Candidiasis & 25 & 24 & 1 & 34 & \# & 11 & 62 & 7 & 26 \\
\hline
\end{tabular}


pose a remarkable risk to contribute to STIs. Women need accurate health education about gynecologic and reproductive morbidity to reduce stigma and embarrassment of RTIs. Health personnel at gynecological department and associated clinics now routinely ask married women if they are experiencing RTI symptoms, a practice that has promoted both education and treatment. Similar education and health care efforts implemented on a wider scale could dramatically improve the health of young women in Nepal.

\section{ACKNOWLEDGEMENTS}

We are grateful to Professor Dr. Ashma Rana and Dr. Archana Amatya TUTH for their help in carrying out the study. Furthermore the authors thank the Department of Community Medicine and Family Health, Institute of Medicine, Maharajgunj, and Central Department of Microbiology, Tribhuvan University for providing laboratory facilities.

\section{CONFLICT OF INTERESTS: None to declare}

\section{FINANCIAL INTEREST: None to declare}

\section{REFERENCES}

1. World Health Organization. Global prevalence and Incidence of selected curable sexually transmitted infections. Overview and estimate. Geneva, Switzerland: WHO, 2001;4:49-13.

2. World Health Organization. Young people and sexually transmitted diseases. Fact Sheet. Geneva, Switzerland: WHO, 1997.

3. World Health Organization. SEAR region update on STIs. New Delhi, India: WHO, 2002;5:12-15.

4. Weinstock H, Berman S, Castes W. Sexually transmitted disease among American youth incidence and prevalence estimates. Perspect Sex Reprod Health 2004;36:6-10.

5. Burathoki K. General profile of STD in Nepal. Country report. Kathmandu, Nepal: Ministry of Health and Population, 1995.

6. Cates W, Rolfs RJ, Aral SO. Sexually transmitted disease, pelvic inflammatory disease and infertility. An epidemiologic update. Epidemiol Rev 1990; 12:199-220.

7. Wasserheit JN. Epidemiological synergy: Interrelationships between human immunodeficiency virus infection and other sexually transmitted diseases. Sex Transm Dis 1992;19:61-77.

8. Mueller DR, Wasserheit JN. The Culture of silence: reproductive tract infections among women in the third world, New York. International Womens' Health Coalition Report, 1991;3-24.

9. Mamdani M. Management of reproductive tract infections in women lessons from the field. In Pachauri S, eds. Implementing a Reproductive Health Agenda in India: the beginning. New Delhi: India. Population
505.

10. Owen MK, Clenney TL. Management of vaginitis. J Am Fam Physician 2004;70: 2125-32.

11. Cheesbrough M. District Laboratory Practice in Tropical Countries. Cambridge University Press 2000;2: 129-390.

12. Pant B. A study on sexually transmitted infections among the patients visiting at Tribhuvan University Teaching Hospital. M. Sc. thesis submitted to Central Department of Microbiology, Tribhuvan University 2000;40-51.

13. Ramsubban R. Patriarchy and the risks of STD and HIV transmission to women. Available from: http://www.cwds.ac.in/library/collection/elib/rts_and_ stds/rtis_patriarchy_and_the.pdf. Accessed may 2012.

14. Prasad JH, Abraham S, Kurz KM, et al. Reproductive tract infections among young married women in Tamil Nadu, India. J Inter Fam Plann Pers 2005;3:73- 81.

15. Bang RA, Bang AT, Baitule M, Choudhary Y, Sarmukaddam S, Tale O. High prevalence of gynecological disease in rural Indian women. Lancet 1989;1:85-88.

16. Passey M, Mgone CS, Lupiwa S. Community based study of sexually transmitted disease in rural women in the highlands of paper New Guinea: prevalence and risk factors. Sex Transm Infect 1998;74:120-127.

17. Younis N, Khattab H, Zurayk H, el-Mouelhy M, Amin MF, Farag AM. A community study of gynecological and related morbidities in rural Egypt. Stud Fam Plann 1993;24:175-86.

18. Barbin L. Reproductive tract infections and abortion among adolescent girls in rural Nigeria. Lancet 1995; 345:300-4.

19. Hawkes S. Reproductive tract infractions. Prevalence and risk factors in rural Bangladesh. Bull WHO 2002;80:180-8.

20. Thomas T, Choudhri S, Kariuki C, Moses S. Identifying cervical infections among pregnant women in Nairibi, Kenya: limitation of risk assessment. Genitourin Med 1996;72:334-338.

\section{Citing this article}

Bohara MS, Joshi AB, Lekhak B, Gurung G. Reproductive tract infections among women attending gynaecology outpatient department. Int J Infect Microbial 2012;1(1);29-33. 